\title{
The Howie code: is the price of safety too high?
}

\author{
DAVID R COHEN
}

From the Health Economics Research Unit, University of Aberdeen, Foresterhill, Aberdeen AB9 2ZD

SUMMARY The code of practice for the prevention of infection in clinical laboratories and postmortem rooms (the "Howie code") was produced in order to standardise laboratory safety procedures $\stackrel{\omega}{\sigma}$ at a level which would minimise risks to laboratory workers. The costs of implementing this code, $\frac{\overline{8}}{8}$ which were not given proper consideration when the code was drawn up, are seen to be very high. $\dot{c}_{j}$ This paper questions whether the benefits of risk reduction resulting from the code can justify the $\underset{0}{G}$ high cost of its implementation.

Beginning with an examination of the incidence in recent years of laboratory-acquired infec- $\frac{\circ}{\infty}$ tions, the paper looks at the perceptions of risk by laboratory workers and the feasibility of low cost alternatives to those of the Howie code. The potential benefits of the code are then viewed against the cost of upgrading the laboratories of two Scottish hospitals to Howie standards.

The fact of high costs relative to benefits reinforces the paper's call for the proper consideration of economic issues to be given at the development rather than the implementation stage of any $\stackrel{\mathbb{S}}{\exists}$ regulatory codes.

Surveys of safety and health care in British medical laboratories $^{12}$ found the incidence of particular infections to be higher among laboratory workers than in the general population, and called for the establishment of regulations for codes of safe practice in clinical laboratories. The well publicised outbreaks of hepatitis in Edinburgh (1969-70) and of smallpox in London (1973) put the Department of Health and Social Security (DHSS) under considerable pressure to produce such a code. The resulting Code of practice for the prevention of infection in clinical laboratories and postmortem rooms, ${ }^{3}$ known as the Howie code, has been subject to considerable criticism since its publication in 1978. This has normally been a form suggesting that the regulations involve costs and inconvenience not commensurate with the risks involved.

The code classifies micro-organisms, viruses and materials into four categories (A, B1, B2, and C) according to different levels of hazard, $A$ being the highest and $C$ lowest, with safety precautions specified for each. Category A pathogens were dealt with in more detail by the Godber Committee; ${ }^{4}$ Howie's main emphasis is on the other three. Materials known to contain hepatitis B virus are placed in

Accepted for publication 20 January 1982 category B1, while those known to contain or sus: pected of containing hepatitis B surface antigen (HBsAg), including all specimens from "at risk" groups, are placed in category B2. These classifications and the associated safety standards, $\stackrel{\odot}{\mathcal{Q}}$ are considered by many to be unnecessary..$^{5-11}$ Soon $\cong$ after the publication of the Howie code, a paper믈 prepared by the Joint Working Party of the Associa- 3 tion of Clinical Biochemists, Association of Clinical Pathologists, Institute of Medical Laboratory Sciences, and Royal College of Pathologists, presented횽 a case for downgrading those hepatitis specimens in $:$ category B2 to category C. ${ }^{12}$ The trade union representing most laboratory workers, the Association of Scientific, Technical and Managerial Staffs (ASTMS), immediately protested against such a응 move. ${ }^{13}$ The controversy on this issue stands at the forefront of discussions surrounding the Howieo report.

The main objective of this paper is to highlight the $\widetilde{N}$ need for an economic appraisal to be conducted N concurrently with the formulation of any code of $N$ practice; in other words that economic appraisal ${ }_{\sigma}^{\omega}$ should be part of the input involved in determining what that code should be. The incidence of infection? among laboratory staff is discussed, followed by an@ examination of the different perceptions of risk by those who face them directly, and by those whoo finance the safety measures. A discussion of alterna- 
tives to a code of practice is followed by an estimation of the costs which would be incurred at two Scottish hospitals if the Howie code were implemented at its most rigid (and expensive) interpretation.

\section{Incidence}

A relevant starting point to this discussion is the fact that the pattern of sickness absence and accidents among clinical laboratory workers is not dissimilar to that of the general working population, and is lower than that for many major employers including the Post Office and London Transport. ${ }^{14}$ Clinical laboratories cannot, therefore, be described as particularly "dangerous" places to work, although surveys have shown that the incidence of particular diseases is higher among laboratory staff than in the general population. ${ }^{12}$ It is a reduction in the incidence of these which is the aim of the Howie code.

This paper places emphasis on the hepatitis B issue, as this has been the main area of contention surrounding the code. It must be borne in mind, however, that the benefits associated with higher safety standards are not limited to those arising from the reduced risk of infection with hepatitis $B$. Table 1 shows the 1979 incidence of other infections among laboratory staff, all of which can be reduced through higher safety standards. The incidence of hepatitis B among laboratory staff since 1970 is presented in Table 2. The figures published in the Communicable Disease Reports ${ }^{20}$ are generally in line with these, and confirm the dramatic post-1974 decline.
Several criticisms can be made of the figures of Table 2, which were determined by responses to a questionnaire sent to members of the Association of Clinical Pathologists (ACP). As there may be laboratories with no ACP staff members it is possible that some were omitted. ${ }^{21}$ Moreover, the accuracy of surveys by postal questionnaire has been strongly challenged. ${ }^{22}$ Though under-reporting is considered unlikely, partly because hepatitis B is a prescribed industrial disease ${ }^{5}$ and more generally because of the "positive interest of members in the survey and its trend," ${ }^{21}$ ASTMS have argued that the figures are "misleading" as they include only cases confirmed by antibody tests, which in some years were not fully carried out. ${ }^{13}$

Recent work has shown that many infections could not be attributed to exposure at work ${ }^{19}$ and it has been suggested that laboratory staff are probably at greater risk of infection in the hospital canteen $^{23}$ or the holiday resort ${ }^{5}$ than they are in the laboratory. The figures of Table 2 must therefore be interpreted as "incidence" and not as laboratoryacquired infection.

A problem can only be said to exist if the laboratory rates are shown to be higher than those of the general population. Both Harrington and Shannon ${ }^{2}$ and Grist ${ }^{19}$ have warned against comparison of their results with any figures for the general population owing to the severe under-reporting expected for the latter. However, the attack rate for bench workers was consistently higher than that for other laboratory staff who are included in the "at risk" figures but who do not regularly come in direct contact with specimens or patients. ${ }^{21}$

Table 1 Cases and attack rates of various infections in laboratory staff, $1979^{15}$

\begin{tabular}{llllll}
\hline Population * $^{*}$ & \multicolumn{4}{l}{ No of infections reported (attack rates $\dagger$ in parentheses) } \\
\cline { 2 - 5 } & Hepatitis $A$ & Tuberculosis & Chicken pox & Salmonellosis and shigellosis & Malaria \\
\hline 11974 & $1(8)$ & $5(42)$ & $4(33)$ & $4(33)$ & $1(8)$ \\
\hline
\end{tabular}

*Includes porters, domestic, office and ancillary staff.

†Per 100000 person years. Person year $=2 / 3 \mathrm{\Sigma}$ (full time + part time/2)

Table 2 Incidence of hepatitis $B$ infection among laboratory staff ${ }^{15-19}$

\begin{tabular}{llll}
\hline Year & Cases & Est No at risk* & Attack rate per 100 000 person-years \\
\hline $70-72$ & 17 & 36893 & 46 \\
$73-74$ & 14 & 22243 & 63 \\
$75-76$ & 3 & 23142 & 13 \\
$77-78$ & 6 & 27175 & 22 \\
79 & 0 & 11974 & 0 \\
\hline
\end{tabular}

*Person year $=2 /, \Sigma$ (full time + part time/2). Prior to 1973 part-time staff not distinguished from full-time staff.

The first period covers three years, the second to fifth periods cover two years each, and the final period covers one year. 
It is difficult from this dicussion to draw firm conclusions about the risks of hepatitis $B$ infection faced by laboratory staff. Laboratory bench workers appear to face increased risks. Despite the current zero incidence it would be wrong to disregard these risks. Nevertheless, there is clearly a need to keep the size of the problem in perspective.

\section{Value of risk reduction}

Risk levels can be determined objectively from incidence rates. The values attached to any reductions in risk levels, however, will always be subjective and will vary depending on the circumstances surrounding the individuals who consider them. These values are not directly proportional to the associated probabilites, and have been shown to depend on several recognised factors, ${ }^{24}$ including the degree of freedom afforded an individual in choosing to accept the risk. It has been estimated that people will accept voluntary risks 1000 times greater than risks imposed on them. ${ }^{25}$ While laboratory workers are, of course, free to change their occupation, or demand a risk premium, ${ }^{26}$ reality tends to make the occupational risk levels faced feel "imposed." It is not surprising, therefore, that "there will always be an irreconcilable difference between the perceptions of what is an acceptable risk by those who are exposed directly to the danger and those who are not." 27 The question then becomes: whose values ought to determine safety policy?

The ASTMS have argued that though the costs of safety cannot be ignored, it is "unacceptable" to expose laboratory staff to the risks of hepatitis when there are means available to reduce them. ${ }^{13}$ Despite the lip service paid to costs, the clear implication is that standards ought to be set independently of resource considerations. With a growing awareness of the scarcity of resources relative to the claims made on them, it is perhaps surprising that the ASTMS view was precisely the one adopted by the working party that produced the Howie code. "No one said to the Howie working party . . . that recommendations or procedures that might cost money should be omitted. Therefore, the authors ... should not be blamed if they ignored 'resource allocation." 28

Resource allocation, however, is not something that can be ignored. While resources are finite, the demands on them are apparently infinite. The allocation of limited resources among competing claims should be based on some rational judgement of where they are likely to produce the greatest benefit. This is particularly relevant to the present discussion, as there is to be no additional central funding for improvements of laboratories to Howie stan- dards. All expenditure must therefore come from existing budgets. If the persistent pleas of economists at least to view the problem in a cost-benefit framework are ignored, then the most efficient use of resources will not be possible.

\section{Alternatives to a code of practice}

While cost-benefit analysis can determine whether a course of action is economically justified, there is another method of economic appraisal, called costeffectiveness analysis, which can find the economically preferred alternative to achieving a particular end, given an a priori decision that the end is worth pursuing. One major alternative to a code of prac- $\dot{\omega}$ tice is the provision of information aimed at increas- 6 ing the use of "common sense" safety precautions such as avoiding use of mouth pipettes or not eating lunch at the work bench.

There is a belief that the greater the awareness by laboratory staff of the hazardous nature of the mat- $\vec{\infty}$ erials they handle, the greater will be the degree of diligence applied to "common sense' precautions, and as a result, the lower will be the number of $\bar{z}$ laboratory-acquired infections. ${ }^{591112}$ This belief $\stackrel{\mathbb{Q}}{\square}$ arises because of the dramatic fall in laboatory infec $\vec{\gamma} \overrightarrow{0}$ tions in the mid-1970s which, it is thought, resulteg from increased awareness of risk after the Londo smallpox and Edinburgh hepatitis incidents, ${ }^{510} \frac{9}{2}$ aided by increased provision of literature on procedures which minimise the dangers of infection. ${ }^{27} 2930$ These procedures can be so effective that two mem- $\frac{2}{\varnothing}$ bers of the working party which produced the Howie code believe that the 1974 Public Health report ${ }^{29} \overline{\bar{o}}$ showed how "simple but effective precautions could 3 almost entirely remove the hepatitis risk." "It seems likely therefore, that education, perhaps coupled with more strictly enforced regulations by safety officers, may prove to be an effective method of risk reduction at a far lower cost than the Howie code. ${ }^{2831}$

Another alternative to a code of practice is a concentration of effort and resources to "raising the 0 standards of technique and accommodation in those places where it is at low ebb."s Such an approach $\frac{7}{0}$ can be justified on equity grounds as it will result in a more equal distribution of risks. It may also prove to $\widetilde{N}$ be an economically efficient method of resource $N$ allocation, if it can be shown that the effectiveness, $N$ in terms of reducing the risk for higher risk laboratories, is greater and/or because the value attached to reducing higher risks is greater.

A code of practice may also be justified on equity grounds; but many laboratories which are low-risk due to staff diligence and common sense will be required by the code to undertake expensive

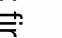
. 
improvements which may only have a very small, if any, effect on their risk levels.

\section{Costs of implementing the Howie recommendations}

This section estimates the costs of bringing the clinical laboratories of two Aberdeen hospitals to full Howie standards. While these estimates are crude, they allow a comparison of numerical cost value with the benefit of Howie, however perceived.

It is not yet known how representative these costs are of laboratories in the UK generally. It is essen- tial to emphasise, however, that the existing risk levels in Aberdeen hospital laboratories are not the determining factor of these costs. Rather, they are based solely on the difference between the code's specification and the current situation regarding layout and equipment. The estimates are crude for the following reasons:

1 The Howie code will, in many instances, act as the catalyst to improvements which were planned or designed anyway. In these cases, though the improvements may not have been realised without the code, it is misleading to label these

Table 3 Costs of raising laboratories to Howie standards (at 1979 prices)

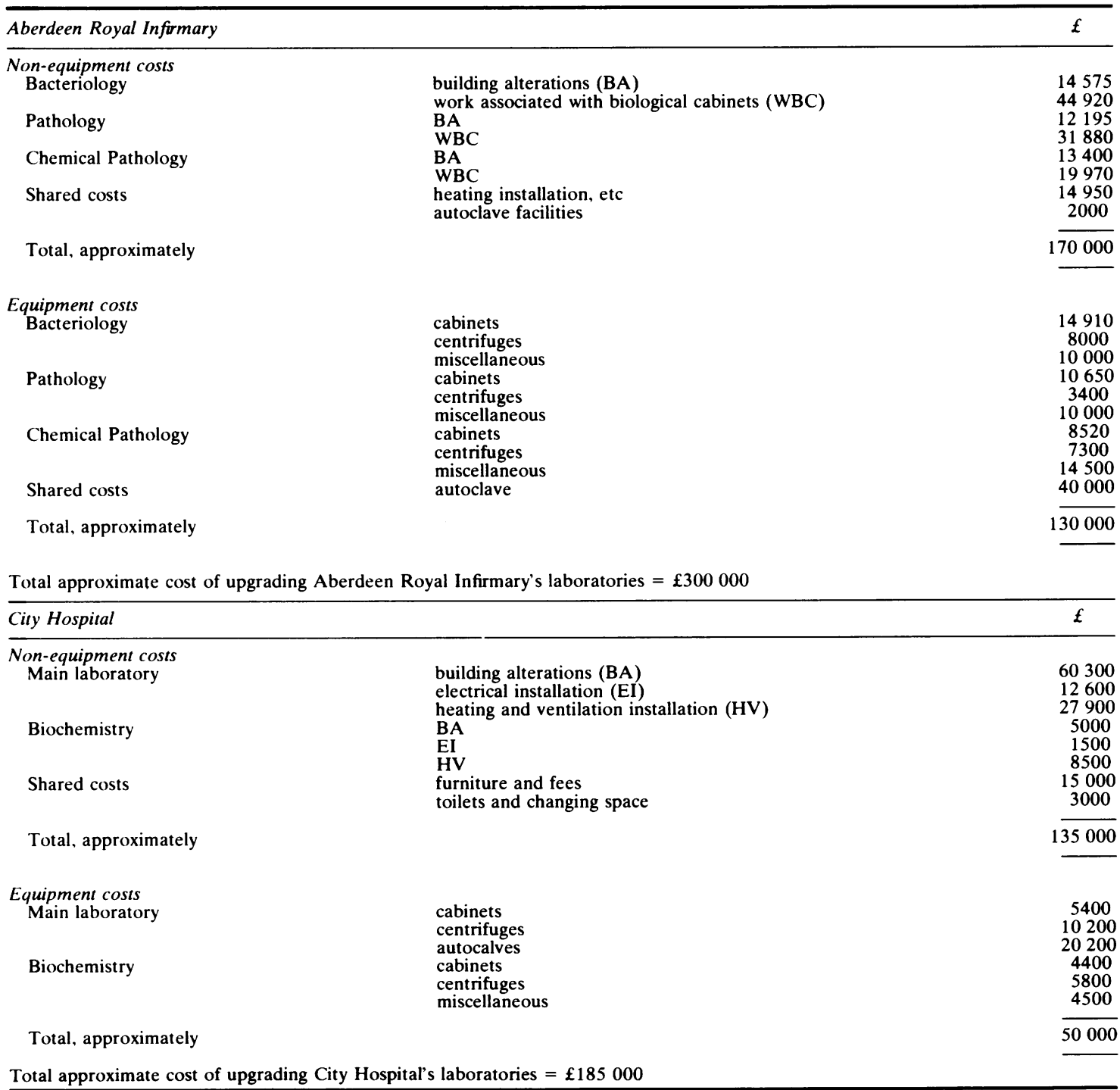


costs as "costs of Howie."

2 Since the Howie code is not specific in the application of many recommendations, different interpretations can change cost estimates dramatically. The figures of Table 3 always assume the most rigorous interpretation and must therefore be regarded as maxima.

3 The status of hepatitis B has not yet been finalised. Table 3 shows the costs with hepatitis B as a category B pathogen, as is currently specified in the code. It is estimated that these figures will be halved if hepatitis $B$ is placed in category $C$. This highlights the need for economic considerations at the development stage of any code.

Given the above, the following cost estimates are presented for two Aberdeen hospitals. All figures are in 1979 prices (excluding VAT). Total figures do not include such running costs as higher electricity costs from operating new equipment, or disposable specimen bags. Additionally it is assumed here, for simplicity, that all equipment life is equal to the life of the laboratory, again resulting in an underestimate of the costs. However, the figures of Table 3 are more than adequate to give examples of the cost of Howie in two situations.

\section{Conclusions}

The upgrading of all clinical laboratories to Howie standards would undoubtedly reduce the risks of infection to laboratory workers. This, however, is insufficient reason in itself to implement the code. The relevant questions which must first be answered are:

1 what are the existing risks facing laboratory workers?

2 what would be the benefits of reducing these risks?

3 what is the cost of achieving this reduction by this particular recommendation?

4 are there alternative methods of achieving an equal risk reduction at lesser expenditure?

This paper has shown that (i) recent incidence of laboratory-acquired hepatitis $B$ infection has been very low, implying that existing standards can reasonably deal with existing risks. This is not to suggest that improved safety standards should be discouraged but that the rewards to any expenditure on safety must be viewed relative to the costs; (ii) the benefits of reducing the risk of hepatitis $B$ infection will be small, given the low incidence level. To this, must be added the benefits of reducing the risk of other laboratory infections; (iii) the cost of implementing this code will vary between laboratories, but could be prohibitive for some. The total for two Aberdeen hospitals alone could be as high as half a million pounds; (iv) there are known alternative measures of safety which could reduce risk at very little cost.

Though this paper does not attempt to present a comprehensive cost-benefit analysis there are clear indications that the Howie code cannot be vindicated on economic grounds. It is not known how the code woud have fared in such an analysis if the hepatitis issue (and particularly $\mathrm{HBsAg}$ ) were treated as a separate item. The conclusions above would certainly not have been as clear.

The controversy which surrounds this code would have been reduced markedly had economic considerations been adequately examined at the planning stages of the code. Resources are finite and, given the alternative uses to which the resources tied up in implementing Howie might be put, it is clear that the optimum level of risk is not zero. The level of safety chosen ought to be decided on the basis of weighing costs against benefits. This Howie failed to do.

I would like to thank $\mathrm{Mr} \mathrm{C}$ Livingston, Safety Officer, Mr P Clark, Deputy Buildings Officer, and Mr C Snape, Assistant Buildings Officer, all of the University of Aberdeen, and Mr E Reid, District Safety Adviser, South District, Grampian Health Board, for their assistance, and the Scottish Homea and Health Department for funding HERU? research.

Any errors are my own as are the opinions expressed which do not necessarily reflect those of Aberdeen University or Grampian Health Board.

\section{References}

' Harrington JM, Shannon HS. Incidence of tuberculosis, hepatitis, brucellosis, and shigellosis in British medical laboratory workers. Br Med J 1976;i:759-62.

${ }^{2}$ Harrington JM, Shannon HS. Survey of safety and health care in British medical laboratories. Br Med J 1977;i:626-8.

${ }^{3}$ DHSS. Code of practice for the prevention of infection in clinical laboratories and postmortem rooms (Howie code). London: HMSO, 1978.

4 DHSS. Report of the working party on the laboratory use of dangerous pathogens (Godber report). CMND 6504. London: HMSO, 1975.

${ }^{5}$ Collins CH. The hepatitis controversy. Medical Laboratory World 1981; Feb:14-9.

- Freeman R, Ingham HR. Dangerous pathogens and the HSE. Lancet 1979;ii:1134.

${ }^{7}$ Heggie JF. Laboratory safety. Lancet 1980;i:210.

${ }^{8}$ Simmons NA. Hepatitis B virus in the laboratory. Lancet $1980 ;$ ii: 1255.

'Brownhill CB. The Howie report. The Medical Technologist 1974; Dec: 46-7.

${ }^{10}$ Anonymous. Hepatitis in laboratory workers: Risks and priorities. Lancet 1980;ii:956-7.

"Howie JW, Collins $\mathrm{CH}$. The Howie code for preventing infection in clinical laboratories: comments on some general criticisms and specific complaints. $\mathrm{Br}$ Med J 1980;280:1071-4. 
12 Joint Working Party of the Association of Clinical Biochemists, Association of Clinical Pathologists, Institute of Medical Laboratory Sciences and Royal College of Pathologists. Stated case for downgrading hepatitis B virus specimens (B2) to category C. London: DHSS, 1980.

${ }^{13}$ ASTMS. The risk of hepatitis to laboratory workers: the case against the attempt to downgrade safety standards in laboratories testing hepatitis B virus specimens. ASTMS: London, 1980.

${ }^{14}$ Grist NR. Letter. Lancet 1979;ii:1244.

is Grist NR. Hepatitis and other infections in clinical laboratory staff 1979. J Clin Pathol 1981;34:655-8.

${ }^{16} \mathrm{Grist}$ NR. Hepatitis in clinical laboratories: a three-year survey. $J$ Clin Pathol 1975;28:255-9.

17 Grist NR. Hepatitis in clinical laboratories 1973-4. J Clin Pathol 1976;24:480-3.

${ }^{18}$ Grist NR. Hepatitis in clinical laboratories 1975-76. J Clin Pathol 1978;31:415-7.

${ }^{19}$ Grist NR. Hepatitis in clinical laboratories 1977-78. J Clin Pathol 1980;33:471-3.

${ }^{20}$ Public Health Laboratory Service. Acute hepatitis B in laboratory staff: reports to the CDR during the epidemiological years mid 1972-1979. Communicable Diseases Reports 1979;79\$48.

${ }^{21}$ Grist NR. Hepatitis infection in clinical laboratory staff. Med Lab Sci 1981;38:103-9.
${ }^{22}$ Collins CH. Letter. Lancet 1979; ii: 1244.

${ }^{23}$ Anonymous. Dangerous pathogens-more thoughts from the HSE. Lancet 1979;ii: 1004.

${ }^{24}$ Cohen D. Prevention as an economic good. HERU Discussion Paper 02/81, Aberdeen 1981.

${ }^{25}$ Starr C. Social benefit versus technological risk. Science 1969;165:1232-8.

${ }^{26}$ Henderson $\mathrm{J}$. The economics of regulating health and safety at work. HERU. Discussion Paper 10/81, Aberdeen 1981.

${ }^{27}$ Collins $\mathrm{CH}$, Hartley EG, Pilsworth R. The prevention of laboratory-acquired infection. London: HMSO, 1974.

${ }^{28}$ Collins CH. Safety on the cheap. Medical Laboratory World 1979; Oct:14-9.

${ }^{29}$ Public Health Laboratory Service. Decrease in the incidence of hepatitis in dialysis units associated with the prevention programme. Br Med J 1974;iv:751-4.

${ }^{30}$ DHSS. Safety in pathology laboratories. London: HMSO, 1972.

${ }^{31}$ Taylor, CED, et al. Letter. Lancet 1980;i:101.

Requests for reprints to: Dr DR Cohen, Research Fellow, Health Economics Research Unit, University of Aberdeen, Foresterhill, Aberdeen AB9 2ZD, Scotland. 